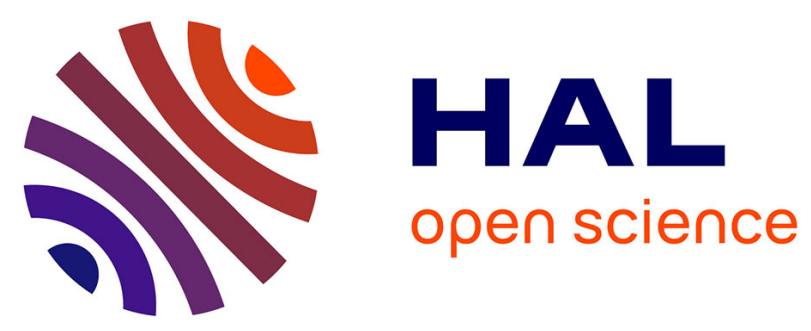

\title{
Nonlinear Regression Modeling to Predict Thermal Endurance of XLPE Material under Thermal Aging
}

\author{
Y. Kemari, A. Mekhaldi, M. Teguar, G. Teyssedre
}

\section{To cite this version:}

Y. Kemari, A. Mekhaldi, M. Teguar, G. Teyssedre. Nonlinear Regression Modeling to Predict Thermal Endurance of XLPE Material under Thermal Aging. 2018 IEEE 2nd International Conference on Dielectrics (ICD), Jul 2018, Budapest, Hungary. pp.1-4, 10.1109/ICD.2018.8514644 . hal-02396153

\section{HAL Id: hal-02396153 \\ https://hal.science/hal-02396153}

Submitted on 25 Nov 2020

HAL is a multi-disciplinary open access archive for the deposit and dissemination of scientific research documents, whether they are published or not. The documents may come from teaching and research institutions in France or abroad, or from public or private research centers.
L'archive ouverte pluridisciplinaire HAL, est destinée au dépôt et à la diffusion de documents scientifiques de niveau recherche, publiés ou non, émanant des établissements d'enseignement et de recherche français ou étrangers, des laboratoires publics ou privés. 


\section{Nonlinear Regression Modeling to Predict Thermal Endurance of XLPE Material under Thermal Aging}

\author{
${ }^{1}$ Y. Kemari, ${ }^{1}$ A. Mekhaldi, ${ }^{1}$ M. Teguar \\ ${ }^{1}$ Laboratoire de Recherche en Electrotechnique, \\ Ecole Nationale Polytechnique (ENP) \\ 10 Avenue Hassen Badi, B.P. 182, El-Harrach, Algeria \\ youcef.kemari@g.enp.edu.dz
}

\begin{abstract}
In this work, the mechanical behavior of XLPE under accelerated thermal aging is investigated. The tensile strength and elongation at break are used as aging markers in order to assess the degradation level of the insulation. In the aim to describe the evolution of the mechanical properties with aging and to estimate the insulation lifetime, a nonlinear regression model is proposed. The model parameters have been estimated using the method of least squares. The experimental results show that thermal aging leads to mechanical degradation of XLPE by decreasing its tensile strength and elongation at break. The critical deterioration of the material was reached at 120 and 140 ${ }^{\circ} \mathrm{C}$. The validity of the regression model was verified and the results show that one-phase exponential decay expression could well fit the experimental data. In addition, thermal endurance of XLPE was investigated using the Arrhenius law. On the other hand, permittivity and $\mathrm{AC}$ conductivity have been monitored in order to study their correlation with thermal aging.
\end{abstract}

Keywords - Electrical insulation; dielectrics; thermal aging; cross-linked polyethylene; power cables; nonlinear regression; thermal endurance.

\section{INTRODUCTION}

Cross linked polyethylene (XLPE), as all other cable insulators are subjected to a diversity of stresses. The thermal stress is one of the most severe service constraints that can lead to the reduction of the cable lifetime [1]. In fact, the electrical and mechanical properties of XLPE can be deteriorated by long-term thermo-oxidation reactions [2]. Some researchers [2, 3 ] have reported that the changes of the chemical structure of XLPE are attributed to chains scission reactions and to the diminution of the crystalline fraction of the insulation material. Therefore, these changes can result in the deterioration of XLPE mechanical characteristics leading to a significant drop of its elongation at break $\left(E_{a B}\right)$ and tensile strength $(T S)$.

On the other hand, the prediction of cables remaining lifetime is nowadays a major challenge. Accelerated thermal aging and Arrhenius model have been widely used by many researchers $[4,5]$ to evaluate the insulation lifetime since the estimation of degradation lifetime at service temperature requires time consuming tests. In addition, the choice of end of life criterion is a very important aspect of applying the Arrhenius model. According to IEC 60216 standard [6], a loss of $50 \%$ of the initial value of $E_{a B}$ or/and $T S$ is considered as end-of-life criterion. Nevertheless, the lifetime threshold at low

\author{
${ }^{2} \mathrm{G}$. Teyssèdre \\ ${ }^{2}$ LAPLACE (Laboratoire Plasma et Conversion d'Energie), \\ Université de Toulouse, CNRS; Bat 3R3, 118 route de \\ Narbonne, F-31062 Toulouse cedex 9, France \\ gilbert.teyssedre@laplace.univ-tlse.fr
}

aging temperatures could not be achieved and an adequate prediction of mechanical properties evolution is needed.

This paper is focused on three investigations; the first one aims to study the effect of the accelerated thermal aging on $E_{a B}$ and $T S$ of XLPE material. The second part is dedicated to establishing a nonlinear regression model which could help to describe the evolution of mechanical properties with aging and to predict the outcome of a lifetime test at low stress levels. Meanwhile, XLPE thermal endurance characteristics have been determined using the Arrhenius law. Finally, the third part presents some dielectric properties characterization results on XLPE. In order to investigate their correlation with thermal degradation, permittivity $\varepsilon_{\mathrm{r}}$ ' (the real part of the complex dielectric constant) and AC conductivity $\sigma^{\prime}$ (the real part of AC complex conductivity) have been monitored at the end of thermal aging tests at each temperature -i.e. after 5040 hours at 80 and $100{ }^{\circ} \mathrm{C}, 4032$ hours at $120^{\circ} \mathrm{C}$ and after 1512 hours at $140{ }^{\circ} \mathrm{C}$.

\section{TESTS AND EXPERIMENTAL METHODS}

\section{A. Material and samples preparation}

In this work, crosslinked Polyethylene XLPE was supplied by ENICAB factory of Biskra, Algeria. The compounded cross-linkable material was of commercial name LE4201R, provided by BOREALIS Company (Denmark). The material contains dicumyl peroxide (DCP) as crosslinking agent and Ditert-butyl peroxide as antioxidant. Pellets were preheated for 5 minutes at $125^{\circ} \mathrm{C}$ then molded and crosslinked at $185^{\circ} \mathrm{C}$ under a pressure of $300 \mathrm{MPa}$ using a pressurized heat press. According to IEC 60216 publication [6], dumbbell samples of $7.5 \mathrm{~cm}$ in length were used for the mechanical tests. On the other hand, electrical measurements were carried out on circular shaped samples of nominal thickness of $2 \mathrm{~mm}$ and a diameter of $46 \mathrm{~mm}$.

\section{B. Accelerated thermal aging}

Thermal aging was performed according to the IEC 60216 standard [6] on vertically arranged XLPE samples inside aircirculating ovens. Three dumbbell samples were taken out every $504 \mathrm{~h}$ (21 days), at temperatures of 80, 100, 120 and 140 ${ }^{\circ} \mathrm{C}$. The aging times were $5040 \mathrm{~h}$ (210 days) at 80 and $100{ }^{\circ} \mathrm{C}$, $4032 \mathrm{~h}$ (168 days) at $120{ }^{\circ} \mathrm{C}$ and $1512 \mathrm{~h}$ (63 days) at $140{ }^{\circ} \mathrm{C}$ corresponding to the mechanical deterioration of the XLPE material as will be discussed later on. 


\section{Mechanical properties tests}

Tensile tests were performed for XLPE samples according to IEC 60811 standard [7] via universal testing machine Zwick/Roell ProLine Z050, as shown in Fig. 1, with a load capacity of $50 \mathrm{kN}$ (available at General Cable laboratory, ENICAB, Biskra, Algeria). All the measurements were carried out at room temperature.

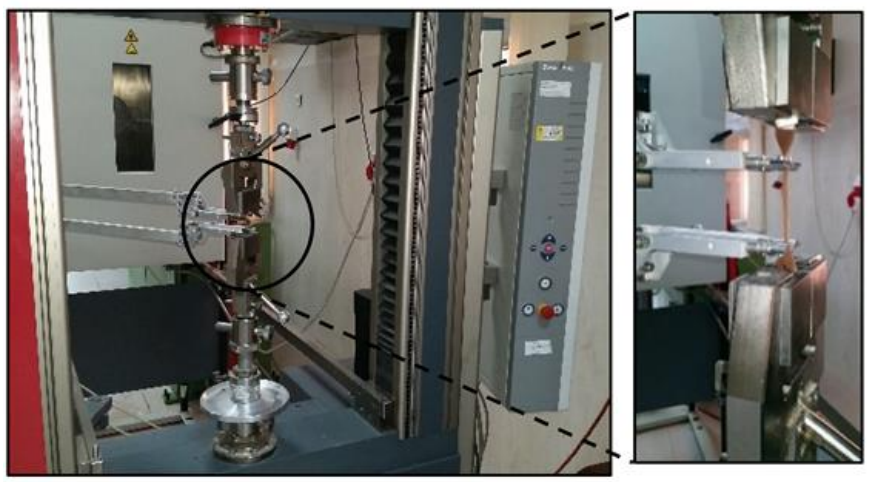

Fig. 1. View of the tensile test machine and the arrangement of the sample.

\section{Dielectric spectroscopy}

Prior to the dielectric measurements, gold electrodes were deposited onto both surfaces of the XLPE circular samples by sputtering. The diameter and the thickness of the sputtered electrodes are respectively $35 \mathrm{~mm}$ and $30 \mathrm{~nm}$. Permittivity $\varepsilon^{\prime}$ and AC conductivity $\sigma$ ' were measured using Novocontrol Alfa-A High Performance Analyzer dielectric spectrometer with a ZGS active sample cell. The measurements were carried out under $\mathrm{N}_{2}$ atmosphere at $20^{\circ} \mathrm{C}$. The frequency varied from $10^{-2}$ to $10^{4} \mathrm{~Hz}$. In addition, the control and the evaluation of dielectric measurements were realized using WinDETA $\AA$ software.

\section{NONLINEAR REGRESSION ANALYSIS}

Nonlinear Regression is used in this work to describe the experimental data of tensile experiments as a mathematical equation. Hence, $E_{a B}$ and $T S$ will be defined as a function of aging time and other fixed parameters. This will lead to estimate the best fitting of the XLPE mechanical behavior on the long-term. Z. Zhang et al [1] investigated the thermal life curve of aged XLPE samples from $110 \mathrm{kV}$ power cable. They proposed a fifth-degree polynomial equation to calculate elongation at break, although, this model contains six parameters to be determined. Besides, polynomial models can give a good fit, but can also substantially diverge outside the defined range of the experimental data. In this study, a single exponential decay function has been chosen. $E_{a B}$ and $T S$ can be expressed by equations (1) and (2) respectively as follows:

$$
\begin{aligned}
& E_{a B} \approx E_{0}-A \cdot e^{\left(t / \tau_{1}\right)} \\
& T S \approx T_{S 0}-B \cdot e^{\left(t / \tau_{2}\right)}
\end{aligned}
$$

where, $E_{0}, T_{S 0}, A, B, \tau_{1}$ and $\tau_{2}$ are the regression parameters. A major aim of the investigation is to estimate the parameters as precisely as possible. For this purpose, least-squares regression technique has been adopted under MATLAB ${ }^{\circledR} 2009$ environment. This technique consists of selecting the parameters that would minimize the difference, or residual, between each data point and the calculated values. Moreover, the criteria that have been used to assess the proposed regression model are: the coefficient of determination $\mathrm{R}^{2}$, the residual sum of squares $(R S S)$, the standard deviation of the model (RMSE) and the analysis of variance (ANOVA) $[1,8]$.

The coefficient of determination $R^{2}$, is defined as the ratio of the residual sum of squares $(R S S)$ and total sum of squares (TSS). The closer $R^{2}$ to 1 is, the more accurate the modelling function is. In addition, the RMSE is a measure of the average deviation of the etimated values from the observed ones.

\section{RESULTS AND DISCUSSION}

\section{A. Tensile experiments results}

Fig. 2 and Fig. 3 present respectively the variation of elongation at break and tensile strength of XLPE samples over aging time at 80, 100, 120 and $140{ }^{\circ} \mathrm{C}$. Each point is represented by the arithmetic average of three experimental values and their standard deviation. In addition, the fitting curves, obtained by the regression method, have been presented with the experimental data by continuous lines.

It can be noticed that the higher the aging temperature is, the more the degradation of mechanical properties is accentuated. For instance, at $80{ }^{\circ} \mathrm{C}, E_{a B}$ and $T S$ remain practically unchanged at the beginning of aging (up to $2520 \mathrm{~h}$ ), then they slightly decrease with aging time. A decrease of 8.42 $\%$ from the initial value has been obtained after $5040 \mathrm{~h}$ at 80 ${ }^{\circ} \mathrm{C}$ for elongation at break and of $18.90 \%$ for tensile strength. At temperature $100{ }^{\circ} \mathrm{C}$, it is found that the drop of $E_{a B}$ and $T S$ with aging time is fast than at $80{ }^{\circ} \mathrm{C}$. $E_{a B}$ decreased from $581 \%$ to $414 \%$ after $5040 \mathrm{~h}$ of aging at $100{ }^{\circ} \mathrm{C}$ (a loss of $28.74 \%$ from the initial value). For TS, it decreased from 20.26 to 13.9 $\mathrm{MPa}$ after $5040 \mathrm{~h}$. However, XLPE samples need to be aged over a longer period to reach the end of life criterion at these relatively low temperatures.

The degradation of mechanical properties at $120{ }^{\circ} \mathrm{C}$ is more significant. $E_{a B}$ decreased abruptly and sharply, as well as $T S$, after $4032 \mathrm{~h}$ of aging. At this stage, the loss in $E_{a B}$ was $92.71 \%$ against $66.73 \%$ in TS. Meanwhile, the degradation of XLPE samples due to thermal aging at $140{ }^{\circ} \mathrm{C}$ was very rapid and intense. Elongation at break and tensile strength reached respectively values of $22 \%$ and $5 \mathrm{MPa}$ within $1512 \mathrm{~h}$. In fact, the described evolution above of mechanical properties for XLPE depends on structural changes in the material [2, 3]. At lower temperatures, 80 and $100{ }^{\circ} \mathrm{C}$, some combined effects of thermal oxidation and cross-linking occur simultaneously at the beginning of aging (up to $2520 \mathrm{~h}$ at $80{ }^{\circ} \mathrm{C}$ and $3024 \mathrm{~h}$ at 100 ${ }^{\circ} \mathrm{C}$ ). The oxidation degradation takes place, but it seems still to have a limited effect [2]. Thereafter, the oxygen diffusion process takes place across the dense crystalline domains, which is a consequence of the continuous but slow decrease of the mechanical properties with aging time. Moreover, the degradation process at $120^{\circ} \mathrm{C}$ becomes faster and more intense due to the auto-accelerated oxidation process. 


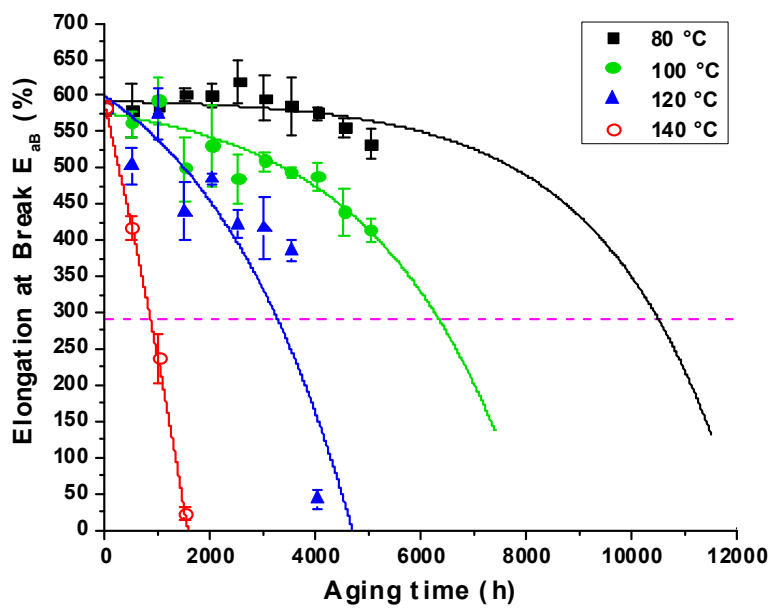

Fig. 2. Variation of elongation at break $\left(E_{a B}\right)$ of XLPE versus aging time. The dashed line defines the end of life.

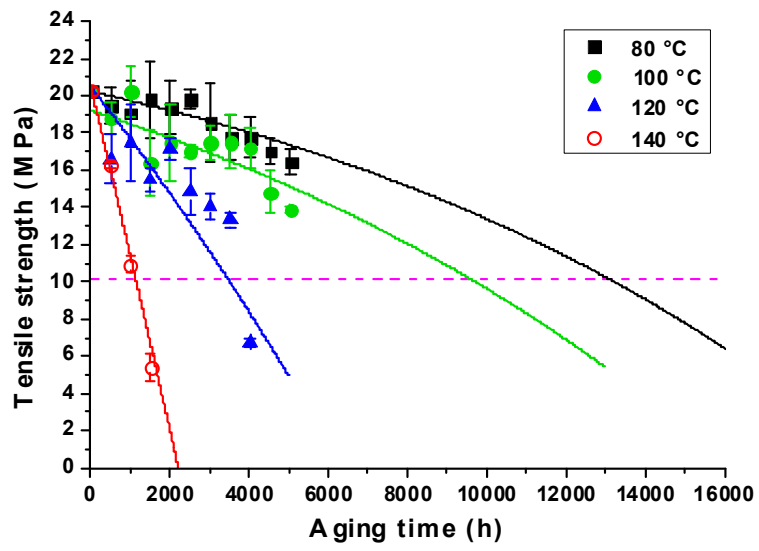

Fig. 3. Variation of tensile strength (TS) of XLPE versus aging time.

The oxidation process is followed by chains scission. The formation of shorter chain segments leads, in relatively short aging time (4032 h), to an abrupt decrease of the mechanical characteristics. Finally, at $140{ }^{\circ} \mathrm{C}$, the oxidation process is dominant and after a relatively short time of aging, $E_{a B}$ and $T S$ drops very substantially. A significant decrease of the crystalline fraction occurs, which makes oxygen diffusion easier leading to chain scission [2].

\section{B. Nonlinear regression results:}

In this part, we present the calculated parameters of the proposed model in addition to the statistical results of the regression method for the studied mechanical properties of XLPE. The obtained results for $E_{a B}$ model (equation 1) are shown in Table I, whereas Table II illustrates the results of TS model (equation 2). It can be noticed that the parameters $E_{0}$ and A change with aging temperature as their sum represents the initial value of $E_{a B}$ before aging. The same observation could be made for $T_{S O}$ and $B$ in the case of $T S$. Besides, the time constants $\tau_{1}$ and $\tau_{2}$ changed slightly at 80,100 and $120^{\circ} \mathrm{C}$, then a significant variation is obtained at $140{ }^{\circ} \mathrm{C}$ meaning that $\tau_{l}$ and $\tau_{2}$ are well correlated with the degradation process. For the statistical analysis, the $R^{2}$ values close to unity and the low $R M S E$ values indicate that a strong correlation exists between the experimental data and expected ones [9].
TABLE I. NONLINEAR REGRESSION RESULTS FOR $\mathrm{E}_{\mathrm{AB}}$

\begin{tabular}{|c|c|c|c|c|c|}
\hline \multirow{2}{*}{$\begin{array}{c}\text { Elongation at break } \\
\text { model coefficients }\end{array}$} & \multicolumn{4}{|c|}{ Aging temperatures $\left({ }^{\circ} \mathbf{C}\right)$} \\
\cline { 2 - 6 } & $\boldsymbol{8 0}$ & $\mathbf{1 0 0}$ & $\mathbf{1 2 0}$ & $\mathbf{1 4 0}$ \\
\hline \multirow{2}{*}{$E_{0}$} & Value & 596 & 604. & 739 & 1779 \\
\cline { 2 - 6 } & Standard error & 4.2 & 7.9 & 22.7 & 133 \\
\hline \multirow{2}{*}{ Value } & 3.73 & 29.2 & 143 & 1198 \\
\cline { 2 - 6 } & Standard error & 0.03 & 23 & 30 & 133 \\
\hline \multirow{2}{*}{$\tau_{I}$} & Value & 2385 & 2666 & 2827 & 3946 \\
\cline { 2 - 6 } & Standard error & 1.5 & 64.3 & 525 & 363 \\
\hline \hline \multirow{3}{*}{$\begin{array}{c}\text { Statistics } \\
\&\end{array}$} & $\boldsymbol{R}^{2}$ & 0.9994 & 0.9472 & 0.8339 & 0.9999 \\
\cline { 2 - 6 } ANOVA & $\boldsymbol{R S S}$ & 9.92 & 5.64 & 188.5 & 0.0164 \\
\cline { 2 - 6 } & $\boldsymbol{R M S E}$ & 0.99 & 0.79 & 5.18 & 0.10 \\
\cline { 2 - 6 } & $\boldsymbol{F}$ value & 10289 & 8980 & 173 & 84371 \\
\cline { 2 - 6 } & $\boldsymbol{P}$ & $2.2 \times 10^{-16}$ & $8.2 \times 10^{-1}$ & $3.4 \times 10^{-6}$ & $2.43 \times 10^{-3}$ \\
\hline
\end{tabular}

TABLE II. NONLINEAR REGRESSION RESULTS FOR TS

\begin{tabular}{|c|c|c|c|c|c|}
\hline \multirow{2}{*}{$\begin{array}{c}\text { Tensile strength model } \\
\text { coefficients }\end{array}$} & \multicolumn{4}{|c|}{ Aging temperatures $\left({ }^{\circ} \mathbf{C}\right)$} \\
\cline { 2 - 6 }$T_{S 0}$ & Value & $\mathbf{8 0}$ & $\mathbf{1 0 0}$ & $\mathbf{1 2 0}$ & $\mathbf{1 4 0}$ \\
\cline { 2 - 6 } & Standard error & 0.20 & 0.71 & 6.6 & 24 \\
\hline \multirow{2}{*}{$B$} & Value & 7.22 & 11.2 & 52.2 & 291 \\
\cline { 2 - 6 } & Standard error & 0.07 & 0.39 & 5.91 & 24.13 \\
\hline \multirow{2}{*}{$\tau_{2}$} & Value & 14970 & 16204 & 19168 & 32394 \\
\cline { 2 - 6 } & Standard error & 64.0 & 262 & 1270 & 1450 \\
\hline \hline \multirow{3}{*}{$\begin{array}{c}\text { Statistics } \\
\&\end{array}$} & $\boldsymbol{R}^{\mathbf{2}}$ & 0.9987 & 0.9876 & 0.9171 & 0.9864 \\
\cline { 2 - 6 } ANOVA & $\boldsymbol{R S S}$ & 6.78 & 69.8 & 144 & 9.10 \\
\cline { 2 - 6 } & $\boldsymbol{R M S E}$ & 0.82 & 2.64 & 4.25 & 2.13 \\
\cline { 2 - 6 } & $\boldsymbol{F}$ value & 10084 & 1292 & 741 & 2158 \\
\cline { 2 - 6 } & $\boldsymbol{P}$ & $2.22 \times 10^{-16}$ & $6.58 \times 10^{-12}$ & $4.02 \times 10^{-7}$ & $4.63 \times 10^{-4}$ \\
\hline
\end{tabular}

Additionally, a high $\mathrm{F}$ ratio and values of $\mathrm{P}$ that are less than the threshold of 0.05 (or $95 \%$ confidence) mean that the model is statistically significant [9]. Therefore, the proposed model for $E_{a B}$ and $T S$ prove to be significant for the estimation of end of life of XLPE due to thermal degradation.

\section{Thermal endurance by Arrhenius model:}

This section aims at estimating XLPE insulation lifetime using mechanical test results and the proposed regression model above. Besides, the Arrhenius model is used for the determination of the thermal endurance curve, which is for expression $[4,5]$ :

$$
t=A \cdot \exp \left(\frac{E}{R \cdot T}\right)
$$

where $t$ is the lifetime, $A$ is a constant, $E$ is the activation energy of the aging process $\left(\mathrm{J}_{\mathrm{mol}}^{-1}\right), T$ is the absolute temperature $(\mathrm{K})$ and $R$ is Boltzmann constant equal to 8.314 $\mathrm{J} \mathrm{mol}^{-1}$. $\mathrm{K}^{-1}$. First, the lifetime was estimated at each aging temperature by using the regression model. In fact, lifetime criterion has been achieved for $E_{a B}$ before $T S$. Then, natural logarithm of lifetime has been plotted versus reciprocal temperature $(1000 / \mathrm{T})$ as illustrated in Fig. 4. The parameters appearing in the equation (3) are determined using linear regression method. Furthermore, the temperature index of XLPE (TI) was obtained by extrapolation of thermal endurance straight line to a lifetime of 20000 hours. The ordinate intercept $\mathrm{A}$ is equal to $8.8 \times 10^{-4} \mathrm{~h}$ the calculated activation energy $\mathrm{E}$ is $11.47 \mathrm{kcal}^{\mathrm{mol}}{ }^{-1}(0.46 \mathrm{eV})$ and $T I$ was found $71.0^{\circ} \mathrm{C}$. The Arrhenius parameters present a good linear regression with $R^{2}$ $=0.91$ as presented in Fig. 4 . 


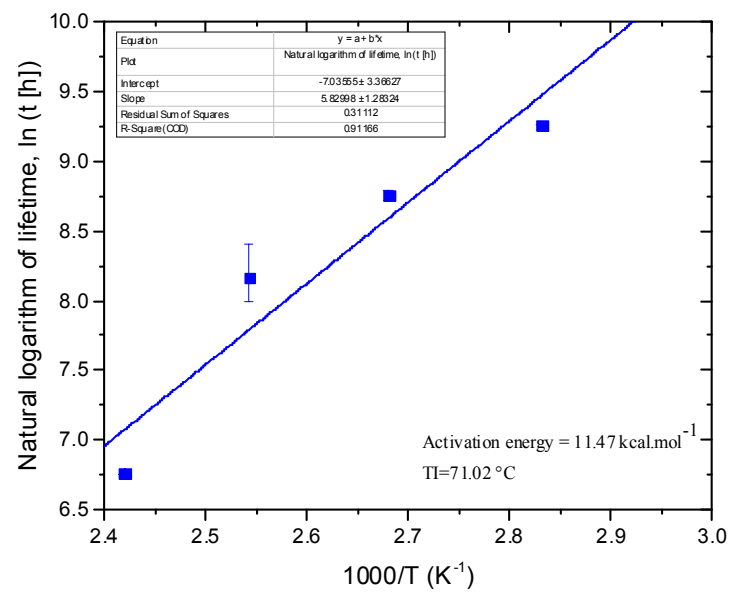

Fig. 4. Thermal endurance graph for XLPE.

\section{Dielectric spectroscopy results}

The variations of permittivity $\varepsilon_{r}{ }^{\prime}$ and AC conductivity $\sigma^{\prime}$ with thermal aging are illustrated in Fig. 5 for $10^{-2}$ to $10^{4} \mathrm{~Hz}$ frequency range. As far as $\varepsilon_{r}^{\prime}$ is concerned, the dielectric constant slightly decreases after $5040 \mathrm{~h}$ of aging at $80{ }^{\circ} \mathrm{C}$, compared to reference material, which could be attributed to cross-linking of the material. After aging for $5040 \mathrm{~h}$ at $100{ }^{\circ} \mathrm{C}$ and for $4032 \mathrm{~h}$ at $120^{\circ} \mathrm{C}$, the permittivity values slightly exceed the ones of unaged sample.

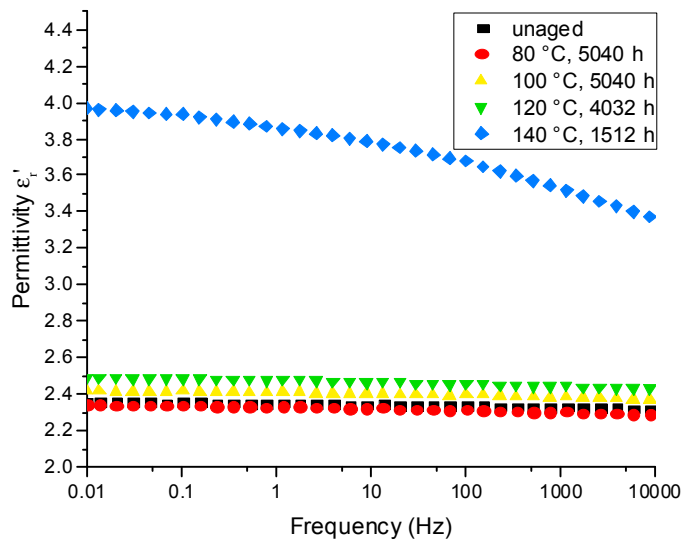

(a)

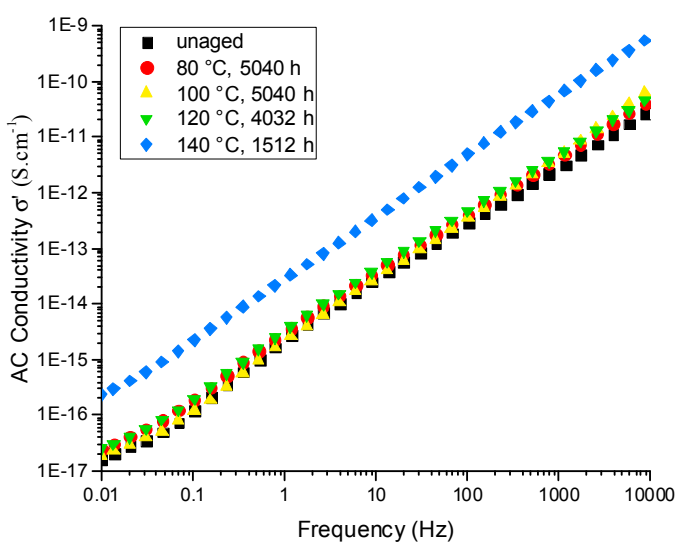

(b)
The increase of $\varepsilon_{r}{ }^{\prime}$ is highly significant at $140{ }^{\circ} \mathrm{C}$ due to the release of carbonyl groups and low molecular weight acid as thermal oxidation products [2,5]. Besides, $\varepsilon_{r}{ }^{\prime}$ is almost unchanged with frequency variations for unaged and aged XLPE samples at 80,100 and $120^{\circ} \mathrm{C}$. A significantly larger dependence has been observed at $140{ }^{\circ} \mathrm{C}$ as the frequency decreases. For the AC conductivity $\sigma^{\prime}$, it can be said that thermal aging yields the greatest influence only at $140{ }^{\circ} \mathrm{C}$ as shown in Fig. 5b which could be explained by chains scission and polar oxidation products. These results are in good accordance with the increase of the AC bulk current which has been investigated in a previous work [10].

\section{CONCLUSION}

A regression method has been successfully implemented in this work to define an aging model and estimate the time needed to reach the end of life criterion for XLPE based on mechanical properties. Additionally, XLPE thermal endurance characteristics have been determined using regression method. The present paper could be extended to develop a phenomenological aging model that can be used for better estimation of the remaining cable lifetime.

On the other hand, the dielectric properties of XLPE are highly affected at $140{ }^{\circ} \mathrm{C}$ (above the melting point) due to oxidation reactions which lead to the decrease of crystallinity and to the release of polar molecules that make raise both polarization and conductivity of the XLPE material.

\section{REFERENCES}

[1] Z. Zhang, P. Assala and L. Wu, "Residual life assessment of $110 \mathrm{kV}$ XLPE cable", Electr. Power Syst. Res., in Press, 2018.

[2] L. Boukezzi, A. Boubakeur and C. Laurent, "Observations on structural changes under thermal ageing of cross-linked polyethylene used as power cables insulation", Iranian Polymer J., vol. 17, pp. 611-624, 2008.

[3] Y. Xu, P. Luo, M. Xu and T. Sun, "Investigation on insulation material morphological structure of 110 and $220 \mathrm{kV}$ XLPE retired cables for reusing", IEEE Trans. Dielect. Electr. Insul., vol. 21, pp. 1687-1696, 2014.

[4] M. Marzinotto, G. Mazzanti, C. Mazzetti, M. Pompili, C. Santulli and P. Schiaffino, "Investigation on thermal endurance of PVC compounds for low voltage cable insulation", Annual Report Conference on Electrical Insulation and Dielectric Phenomena, pp. 49-52, 2007.

[5] G.C. Montanari and A. Motori, "Thermal endurance evaluation of XLPE insulated cables”, J. Phys. D Appl. Phys., vol. 24, pp. 1172-1181, 1991.

[6] IEC 60216, "Guide for the determination of thermal endurance properties of electrical insulating materials. Part 1: General guidelines for aging procedures and evaluation of test result", $4^{\text {th }}$ Issue, 1991.

[7] IEC 60811, "Common test methods for insulating and sheathing materials of electric cables and optical cables", 2001-07.

[8] Z.Sahli, A. Mekhaldi, R. Boudissa, and S. Boudrahem, "Prediction parameters of dimensioning of insulators under non- uniform contaminated conditions by multiple regression analysis," Electr. Power Syst. Res., vol. 81, pp. 821-829, 2011.

[9] A. Shirkovets and A.Telegin, "Accelerating dielectric response measurements on power transformers-Part II: a regression approach", IEEE. Trans. Power Deliv., vol. 29, pp. 2095-2100, 2014.

[10] Y. Kemari, A. Mekhaldi and M. Teguar, "Experimental investigation and signal processing techniques for degradation assessment of XLPE and PVC/B materials under thermal aging", IEEE Trans. Dielectr. Electr. Insul., vol. 24, pp. 2559-2569, 2017.

Fig. 5. (a) Permittivity $\varepsilon_{r}^{\prime}$ and (b) AC conductivity $\sigma^{\prime}$ of XLPE versus frequency at different aging stages. 